\title{
On the pregnance of bodily movement and geometrical objects: A post-constructivist account of the origin of mathematical knowledge
}

\section{Wolff-Michael Roth}

Abstract: Traditional (e.g., constructivist) accounts of knowledge ground its origin in the intentional construction on the part of the learner. Such accounts are blind to the fact that learners, by the fact that they do not know the knowledge to be learned, cannot orient toward it as an object to be constructed. In this study, I provide a phenomenological account of the naissance (birth) of knowledge, two words that both have their etymological origin in the same, homonymic Proto-Indo-European syllable ĝen-, ĝena-, ĝne--, ĝnō-. Accordingly, the things of the world and the bodily movements they shape, following Merleau-Ponty (1964), are pregnant with new knowledge that cannot foresee itself, and that no existing knowledge can anticipate. I draw on a study of learning in a second-grade mathematics classroom, where children (6-7 years) learned geometry by classifying and modeling 3-dimensional objects. The data clearly show that the children did not foresee, and therefore did not intentionally construct, the knowledge that emerged from the movements of their hands, arms, and bodies that comply with the forms of things. Implications are drawn for classroom instruction.

Keywords: pregnance, naissance, knowledge, cognition, movement 
Critiquing the "little man that is in man,"-perception as knowledge of an object-finding again man finally face to face with the world itself, finding again the pre-intentional present, - is to find again this vision of origins, that which sees itself in us. (Merleau-Ponty, 1964, p. 258, original emphasis, underline added).

In many theoretical approaches-including constructivist, enactivist, and embodiment theories-relations are postulated between the body and knowledge. In this introductory quotation, Merleau-Ponty notes the requirement to critique the (constructivist) idea of the homunculus in all of us who constructs the knowledge as reflective subject, who applies schemas (concepts) to the world it perceives. What is required instead is an understanding of human knowledge as arising from the confrontation of persons with the world in a pre-intentional present, pre-intentional because what we will have learned lies by definition outside our previous knowledge and therefore cannot be intended. Studies associating themselves with the constructivist, embodiment, or enactivist approaches emphasize sensorimotor activities. However, the emphasis on the "motor" aspects of human behavior misses precisely what is most important about movement: kinesthesia. Thus, "to arrive at veritable understandings of kinesthesia and the fundamental concepts generated in and through movement, embodiers need to wean themselves away from sensory-motor talk" (Sheets-Johnstone, 2010, p. 221). Instead, what needs to be done is describing and working on the basis of sensory-kinetic experiences. Researchers need to think in terms of movement itself instead of schemas and other transcendental (abstract and abstracted) forms that somehow need to be embodied (put back into a body) and enacted. Movement, on the other hand, and the associate feeling of movement, kinesthesia, essentially implies the body and, on evolutionary grounds, is a condition of life and cognition (Leont'ev, 1959). Thus, it makes little sense to talk about movement in the absence of bodies. Living consciousness, and therefore cognition (knowing and learning) essentially derive from kinesthesia, "our tactile-kinesthetic . . consciously felt moving bodies" (Sheets-Johnstone, 2010, p. 227) rather than from purely motor aspects or motor aspects associated with sensations. Instead of a "motorology," we need to pay attention to the "living and lived-through dynamics as it unfolds and of that living and livedthrough dynamics as a kinetic melody" (p. 230). Therefore, it is not so much the physical body that needs to be theorized to understand cognition-knowing, learning, education-but movement and kinesthesia. This would then allow us to distinguish (a) robots that learn bottom up from interacting with their physical and "social" environment, but do not have kinesthetic forms of experience from (b) animate beings that are and feel alive (Ingold, 2011). 
Other recent work on cognition and learning, such as the work on the situated, embodied, and enacted nature of cognition places, also an emphasis on the body (e.g., Roth \& Jornet, 2013). In the present study, no recourse is sought to embodiment, enaction, or schemas that are central features in recent discourses that seek to integrate cognition and animate bodies. I develop instead a phenomenological account that is fundamentally grounded in movement, the associated feeling thereof (kinesthesia), and the sensation that arises from tact and the contact of the moving body with the surrounding world at its sensory periphery. That is, although the proposed conceptualization of learning is grounded in bodily movement, it distinguishes itself from other theories because it explains those aspects of knowing that the embodiment and enactivist approaches presuppose.

In the chosen approach to education and learning, experience in and with the world begins with and precedes intentional orientation towards readymade objects. The structure of this article follows this temporal relation of and between experiences and events and the knowledge thereof. Thus, I begin with the empirical description and then proceed to an unfolding, deepening analysis of what we can see and learn from the episode presented.

\section{On the birth of knowledge}

\section{Introduction}

The dominant educational ideology conceives of learning in terms of the intentional construction of knowledge. Several studies showed, however, that the source of thinking, knowing, and learning is pre-reflective, which gives an essentially passive dimension to learning (Husserl, 1973; Petitmengin, 2007). Empirical work, too, provides evidence that learners, precisely because they cannot see beforehand the knowledge that will have been learned at the end of or following some task: That which will have been learned is unseen and therefore unforeseen prior to and during the learning episode (Roth, 2012; Roth \& Radford, 2011). In fact, the terms knowledge (as cognition) and naissance (birth) have the same origin. Both derive from the homonymic syllable ĝen-, ĝena-, ĝne-, ĝnō-. One of the two homonyms has the signification of "to bear," "to generate," and makes it into Latin as nātu, and, from there, via the French, develops into the modern words naissance, naissant, née, nascence, and nascent. In another line of linguistic evolution, the same aspect of the root develops into the birth-related words genesis and generate. The second part of the homonym has the signification of "to know," "to recognize." In fact, both verbs - "to know" and "to recognize"-and the nouns and adjectives built on these, directly derive from the root. The verb "to can" (and its equivalent verbs in numerous Germanic languages) as well as the adjective/noun "gnos- 
tic" (relating to knowledge) have the same origin. That is, there is an historical association of knowledge, on the one hand, and naissance (birth), on the other hand. Knowledge is birth: It comes forth from the pregnance of movement. The difference between knowledge and naissance is undecidable. Knowledge is born in movement, because knowledge, unlike what Piaget and all sort of other constructivists think, is not somehow abstracted from movement but is born in an excess of movement pregnant with the new. That is, "in the thinking of the body, the body forces thinking always farther, always too far . . . This is why it makes no sense to talk about body and thinking apart from each other" (Nancy, 2000, p. 34). In English, the term reconnaissance, a term born from the same Proto-Indo-European root, refers to an advance into a terrain to discover its nature prior to making the real advance: it is a movement ahead of itself. In reconnaissance, as in Melissa's movements described in the following empirical case, knowledge is born in a movement of transcendence, when aspects of movement come to stand out and against itself in awareness. A deterritorialization of the movement takes place, from doing work to symbolizing the work and its results. Just as in any birth, that which is born, here knowledge, cannot anticipate itself; coming among its own, knowledge will not have foreseen itself. In the following, a case study is provided of how the new and unforeseen arises in and from movement.

\section{An Empirical Case}

The empirical materials that follow were collected in the course of a specially designed unit on three-dimensional geometry for second-grade students (e.g., Roth \& Thom, 2009b). The study results show that through this curriculum the children came to work at developmental levels with respect to three-dimensional geometrical objects beyond the levels that the relevant theoretical models by van Hiele and Piaget attributed to that age (Roth \& Thom, 2009a). The unit, which stretched over a three-week, 5-days-perweek, 70-minute-per-day period includes tasks in the course of which children explore and talk about three-dimensional objects in small-group and whole-class configurations. For example, in the first lesson, the children were asked to sort, one object at a time, mystery objects and, in so doing, to build a category system (Roth $\&$ Thom, 2009b). In the lesson from which the data presented here derive, the students were asked to gather in groups of three and to build plasticine models of a mystery object hidden in a shoebox and accessible only to tactual experience by entering a hand through a narrow hole in one of the walls covered by a curtain. One of the cameras used in the research project followed the group including Sylvia, Jane, and Melissa. The following description centers on Melissa. 
The video shows that Melissa, after having her hand in the shoebox for 12 seconds (Figure 1), laughs, as if some idea had come to hear; and she then begins to work her mass of plasticine. The latter slowly takes what we recognize to be cubiform shape. About 2:30 minutes later, Melissa says to Jane, "You know what is, I think it is a cube." Jane exhibits a questioning facial expression and Sylvia, while having her hand inside the shoebox, responds while shaking her head: "It's not a cube." About 15 seconds later, Melissa turns towards Jane and, saying "I checked the sides like this," moves her cubiform model exposing one face, holding the thumb and index finger of the left hand in a caliper configuration to it, then continuing to rotate the cube to expose the next side, again holding the caliper configuration to it (Figure 2).

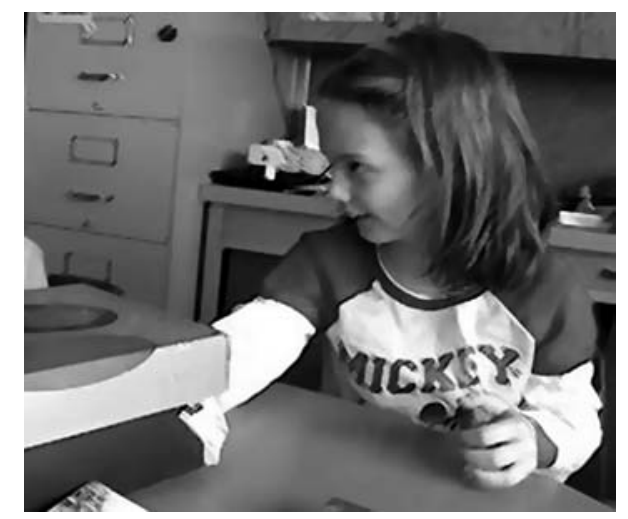

Figure 1: Artistic rendering of the instant when Melissa initially enters her right hand into the shoebox where there is a mystery object.

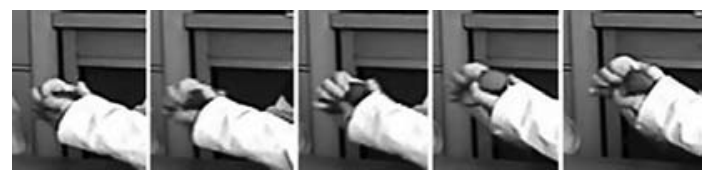

Figure 2: Melissa moves the cube to expose one face orthogonal to the first, in each case holding the thumb and middle finger of the right hand in a caliper configuration.

Another 90 seconds later, Melissa holds up the plasticine model that she has continued to fashion towards the research assistant shooting the video and says, "I think it is a cube." The research assistant asks, "Why do you think it is a cube?" As before, Melissa brings the right hand into a caliper configuration holding it across one face of the cube (Figure 3a), then, turning the cube to expose a second face orthogonal to the first one, she 
holds the same, unchanged caliper configuration to it (Figure 3b). She turns the cube again, exposing a face orthogonal to the second one (Figure 3c), and finishes exposing the first face while holding the caliper configuration against it (Figure 3d).

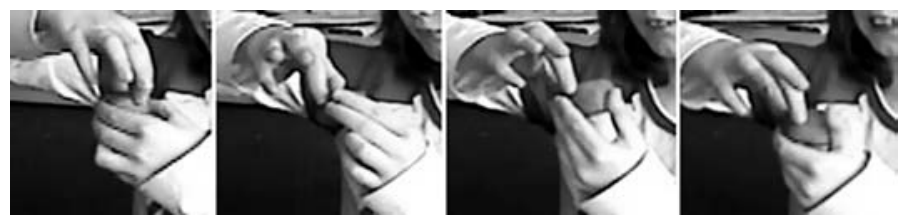

Figure 3: "Because it is the same . . . because it is the same . . shape."

Following this second articulation of the object, having gone through another episode of entering and presumably exploring the mystery object (we do not know what the movements actually are), Melissa goes through the same kind of movements again about 2 minutes later. She turns the cube while holding the fixed caliper configuration to the different sides of the cube. The research assistant asks, "What does it have to have to be a cube?" Melissa responds, while moving the cube and holding a caliper configuration to the different face pairs, "It has to have the same . . . sides" (Figure 4). Following exchanges with her peers, who assert that they do not think that it is a cube and describe to/instruct Melissa what and how to do feel that the mystery object has the shape of a (flat) rectangular prism. For example, Sylvia repeatedly configures her two hands in a praying position, which we can see as descriptions of/instructions for sensing the flatness of the mystery object. However, Melissa appears in a position not unlike the infant, whose "actual transfer of sense from the visual body of another to its own tactile-kinesthetic body is unexplicated" (Sheets-Johnstone, 2010, p. 230). Our account therefore will have to provide an explication of the conditions under which Sylvia's descriptions can make any sense to Melissa.

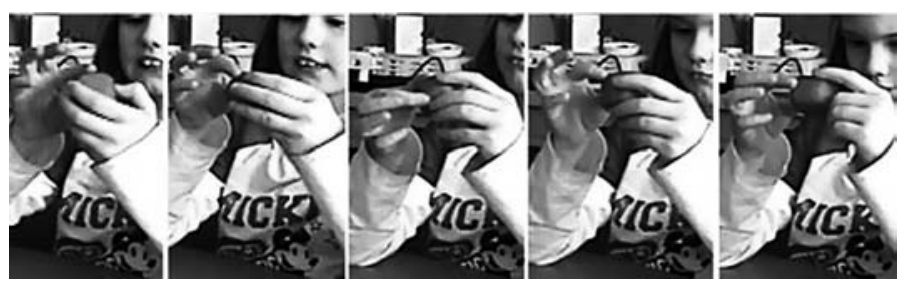

Figure 4: "It has to have the same . . . sides." Melissa applies the caliper configuration to a face and then turns the cube to apply the same configuration a face orthogonal to the former. 
The research assistant subsequently asks Melissa, "Why do you think it is the same?" Melissa's hand moves through a variety of configurations as if she were moving about the different faces of a cube and says, "I feel all around it and it is the same" (Figure 5).

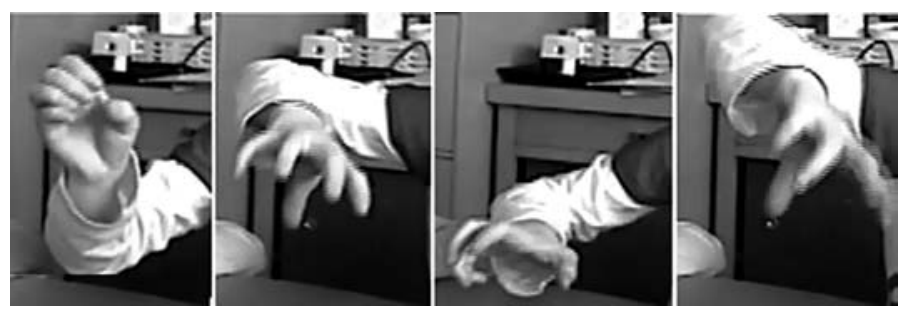

Figure 5: "I feel all around it and it is the same."

Eventually the teacher arrives at the table (9:50 minutes into the task). At that time, Melissa goes through the same movements again, turning the cube in and with her left hand to expose different faces, and holding a caliper configuration across pairs of sides, saying that it has to be the same. The teacher, however, who has grouped the Sylvia's and Jane's models separate from that Melissa has shaped, suggests that the three need to come to agree on one solution to the task: There is only one mystery object and, therefore, there can be only one type of model. After repeatedly rearticulating her assertion about the cubiform nature of the mystery object, Jane eventually takes Melissa's model in her left hand, moves and touches it while having her right hand in the shoebox. Jane asserts that that the mystery object is not a cube, and, as Sylvia before, invites Melissa to do a comparison using her model.

Melissa takes Jane's model in her left hand and enters her right hand into the shoebox (Figure 6a). We can see the left hand moving: rotating/touching the model with one of the large square faces pointing upward. Jane, with an open palm, touches the exposed face and suggests, "Feel this part" (Figure $6 \mathrm{e})$. Jane suggests turning the model on the other side. We again observe movements, which hold and turn over the model, followed by a touching movement (Figure 6i). As a result of the next movement, the model comes to stand on one of its narrow faces (Figure 6j), followed be a series of movements that rotate and feel the object (Figures $6 j-n$ ). Melissa then directs her gaze-which up to this point was oriented toward Jane's model in front of her-into the air, puckers her lips, and begins to grin in an apparent expression of surprise; in continuing the movement, she returns the model to Jane and then immediately begins to reshape her cubical model, which eventually takes on a rectangular prismic form. 


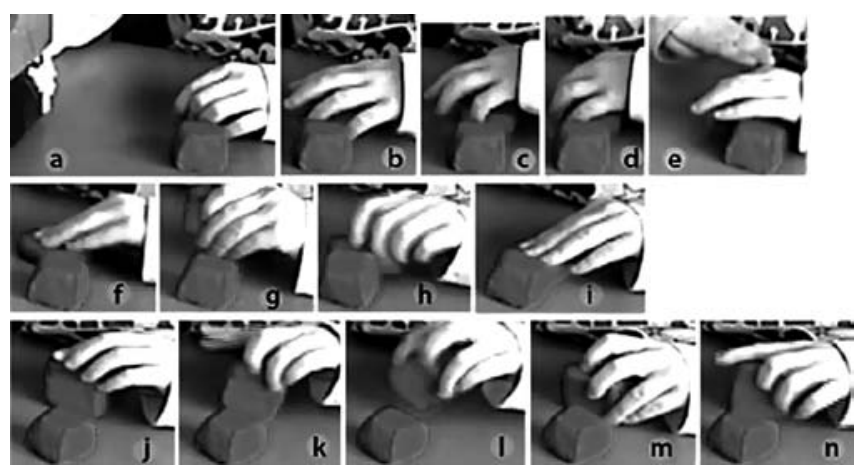

Figure 6: Melissa moves the object and feels it while her right hand is inside the shoebox: a-e. On one of the flat sides, she feels and turns the object four times. f-i. Turning it over, she feels the other flat side. j-n. Putting it on the narrow sides, she feels and turns Sylvia's model six times.

From the instant when Melissa first put her hand into the shoebox to the second idealization of the nature of the mystery object, exactly 15:00 minutes had passed, during which Melissa had reached a total of 8 times into the box for a total of 3:10 minutes. In this episode, a new form essentially arises twice-first the "cube" then rectangular sold-from, and is wedded to, the movements of the left arm, hand, and fingers, which, presumably, parallel the movements of the right hand and fingers. The shape that emerges has its origin in proprioception, the kinaesthetic experience, and the associated sensory experience deriving from the meeting with the material object.

\section{Recon/Naissance: From first movements to symbolic gestures}

In the preceding case study, the rectangular prismic form emerged in, through, and indissociably from the movements of the hands, inside and outside the box. It is indissociable from the movements, because any denotation of the form by means of one or the other sign (e.g., word, model, symbolic gesture) is grounded in the preceding experience. The associated movements, when mobilized again outside the box to show what she has done (Figure 5) and why it is a cube (Figures 2-4), reproduce a kinaesthetic experience. But such movement does not require cogitation and awareness. Rather, just as we walk without having to think how and where to place our feet, the memory of the movement is sedimented in the movement, which can be reproduced at any one point in time and, thereby, lead to the same kinaesthetic experience: alone, in the absence of the object, to the sensations in the presence of the object. In fact, the naissance of form (i.e., idea, 
knowledge) occurs twice in the episode: first, when the cubical form emerges from the movements in the initial encounter and, second, when the rectangular prism form emerges during the eighth comparative exploration of the mystery object together with Jane's model. As the following analyses show, this is not embodied experience; it is the experience of a body in movement (Sheets-Johnstone, 2011). Everything we see in Melissa is movement, from the first demonstration of how she knows that the mystery object is a cube to the exposition of how she had previously investigated the mystery object (Figures 2-5), to the repeated exploration of the mystery object in the right hand and the comparison objects in the left hand (Figure 6). Over 200 years ago, another phenomenological philosopher had already noted the role of the sense of effort to learning, a sense that is source of the subject itself because of the distinction between the subject of the free effort and the term that immediately resists with its own inertia (Maine de Biran, 1859a). Here, I develop a phenomenological account of learning, which takes into account the empirically demonstrated fact that without bodily movement no knowledge is observed (e.g., Hein \& Held, 1963). Knowledge is born (née) in movement.

In classical epistemologies and associated constructivist research projects, such as those of Piaget, objects are given as such. That is, children and other learners, such as those we followed in this project, are assumed to be interacting instantaneously with objects as wholes (e.g., "cube" or "rectangular prism"). However, in the episode, Melissa could not have interacted with the "mystery object" as one thing, but rather, as shown in her hand movements (Figure 5), there has been a sequence of movements turning (about) the object. At best, there are the experiences of a series of facets. These experiences have integral and irreducible kinesthetic and sensory dimensions. The video shows how Melissa, with a facial expression of concentrated and focused activity, apparently moves about in the box. Then, suddenly, she breaks into a smile. She withdraws her hand and, eventually, tells Jane with accompanying hand movements why the mystery object has to be a cube (Figure 2). The same is observable in the symbolic constitution of the object through the hand movements in the presence of the cubiform model. Finally, the new form emerges from unfolding movements that follow each other rather than being present and presented instantly. At the heart of our coming to know an object, there is therefore a sequential set of movements that come to be coordinated to make the object as such. What is coming to be known exists in and arises from the series of movements. Knowing the object means knowing how a facet changes into another facet. Thus, for example, the rectangular prism-recognized as such at the moment marked by surprise-emerges from a sequence in which first one of the large faces, 
then its opposite, then the sequence of narrow faces come to be in contact with the fingers. The specific form arises from and is constituted by knowing what happens when the object is turned and followed along, turned and followed along, turned and followed along. That is, when Melissa explains why the mystery object is a cube, she expresses it in a sequence of movements rather than in the geometer's abstract properties (e.g., "6 equal squared faces" or "an object with $\mathrm{O}_{\mathrm{h}}$, *432, or achiral octahedral symmetry"); but without such experiences, none of the formal, abstract properties would make sense.

The foregoing actually is reminiscent of the celebrated but in education little attended-to analysis of the experience of a cube (Merleau-Ponty, 1945), only recently confirmed as correct by neuroscientists (Rizzolatti, Fadiga, Fogassi, \& Gallese, 1997). Accordingly, we never experience a cube as such, that is, a cube as geometry theorizes it but rather experience it under a given horizon and in the form of a particular perspective (e.g., a hand holding a caliper configuration to a side [Figures 2-5], or the fingers or palm pressing down on the exposed face of a rectangular prism [Figures 6e, f, i]).

When Melissa first puts her right hand in the shoebox, she does not and cannot know what the mystery object is. In moving about, the hand eventually comes into contact with a mass different from and detached from the shoebox. But this mass does not and cannot appear as a completed formcontradicting Piaget who asserted that we can perceive whole forms. To have any hope of finding out what kind of object is in the box, Melissa's hand needs to move over, about, and around it. There are two experiences that arise for her (hand): those deriving from the auto-affection of the animate body (i.e., kinesthesia) and the sensory ones deriving from the contact with the material world. Only the latter had been associated with knowledge, made thematic as epistemic movements. Whatever the form that eventually emerges, it is the result of a series of movements, of movements connected by movements - which may be of the object turned about itself or of a stationary object with the hand moving about it. Before she senses the mystery object for a first time, Melissa's hands cannot enact the symbolizing movements that we subsequently see (Figures $2-5) .{ }^{1}$ The required sensation of movement, kinesthesia, comes from the first execution of the movement - i.e., reconnaissance - to be subsequently recognized in its reproduction, rather than having its origin in the brain. We may think of this as a series of innervations; and this series constitutes something like a kinetic melody

\footnotetext{
As relatively recent neurophysiological research has shown, recognition of movements and symbolic movements are possible only when there are neurons that mirror those responsible for the movement (Rizzolatti, Fadiga, Gallese, \& Fogassi, 1996).
} 
(Sheets-Johnstone, 2009). Once triggered, the movement as a whole unfolds without requiring any further outside control. ${ }^{2}$ This is why the movement can be executed again on the basis of what the organs "know" themselves, and even the knowledge that the present movement is the same as a preceding one is based on the kinesthetic sense. Conscious will does not determine the movement of an organ: Consciousness intervenes to get the movement going and recognizes subsequently, in the effect of the movement, whether the intended and the actual movements have been the same.

As a consequence of the movements, something whole comes to establish itself, an idea, which goes beyond (i.e., transcends) the actual kinesthetic and sense experience - like the experiences of the blind men in the wellknown story from the Indian subcontinent who touch an elephant, even though in the case of each it is a different whole. The fact that Melissa does not anticipate either the cubiform or the rectangular prismic experience can be seen from the facial expressions, which, in each case, express that something unforeseen has been arriving. The intentional orientation towards the mystery object as an object of a specific type- in Melissa's case, a cube cannot but exist after its initial constitution. It is the result of a series of movements and the associated kinaesthetic and tactile experiences. And all the signs available on the videotape speak for a passive rather than an active constitution: the first as the second idea come to Melissa rather than being the result of a construction - consistent with the way in which (novel) insights arise in problem solving (Petitmengin, 2006). In that movement of an idea that emerges to become itself - a movement we may term ideation - a new quality to the subsequent movements related to the mystery object comes about. The new can come about because "the intention in effect never limits itself to vision of that which is seen by it" (Henry, 2000, p. 53). This leads to the fact that "that which is seen, to the contrary, is of such a nature that one has to discern in it that which is really seen, given in itself, 'in person,' and that which is but 'emptily aimed at [visé à vide]"' (Henry, 2000, p. 53). At the instant Melissa aims at the mystery object "knowing" that it is a cube, only one of its sides at a time is self-evidently given, "whereas the others are aimed at without really being given" (p. 53).

Recent work in anthropology has suggested the differentiation between transitive and intransitive action (Ingold, 2011). In transitive action, there are starting points (intentions, goals) and endpoints (outcomes), like the bridgeheads that connect the two sides of a river. Intransitive action, however, is transversal to the first, occurs in any case and despite intentions

2 This is also a reason for the observed gap between explicit, mental plans and situated actions (e.g., Suchman, 2007). 
- it corresponds to the transversal lines of flight [lignes de fuites] (Deleuze $\&$ Guattari, 1980). These lines of flight are but another way of naming the deterritorialization of movement. Intransitive action, lines of flight, or deterritorialization is generative, but in the sense of proliferation and excess, where the new cannot ever be anticipated based on what is known before.

When Melissa moves her hand through a series of positions, symbolically indicating what she has done (Figure 5), the kinaesthetic experience is reproduced but the sensation of the mystery object is absent. On the other hand, the symbolic movements in the presence of the cubiform model not only reproduces kinaesthetic experience but also the sensory experience that goes with the contact. There is therefore an abstraction in the sense that the object no longer is present but the movement still underlies the symbolic form produced in and through the gesture. That is, the hand movement makes the object present again, perceptually to the eye, in its absence: it represents the object independent of the place in the shoebox where it was originally found and felt. We therefore do not need to speak of the enactment of a schema or the embodiment of the cube and rectangular prism because the movement itself constitutes the original and originary memory of the associated forms. ${ }^{3}$ Arising out of the contact with the world, the movement has become independent of it, constituting its own memory, and, thus, exists abstracted from the situation. Melissa can show what she has done later in a whole-class session, away from the particular object and in a different part of the classroom. She might even return home after school and go through the same movements again to show to her parents what she has done on that day in the mathematics classroom.

There is a problem when we theorize thinking and learning through the processes Piaget and constructivists following him propose. Thinking learning through assimilation and accommodation actually destroys the internal structure of the object for the experiencing subject (Merleau-Ponty, 1945). Thus, a cube never is perceived in terms of its geometrical qualities, six equal square faces, eight vertices, twelve edges, 90 degree angles, and so on. Thus, "the cube with six equal faces is only the limit idea by means of which I express the carnal presence of the cube, which is there, under my eyes, in my hands, in its evidentiary presence" (p. 236-237). I never perceive the cube or its projections but always the concrete properties of the thing. More importantly, when I hold the cube in my hand, turn and feel it, "I do not construct the idea of the geometrical that gives reason to the perspectives, but

3 If schemas existed, high-performance athletes could articulate, by the very nature of schemas as something transcendental, the difference between their movements and those of another athlete coming in second. But athletes or scientists studying them cannot articulate in just what the difference exists. 
the cube is there before me and discloses itself through them" (p. 237). I do not have to objectify and look at my experience from the outside to discover the cube behind, so to speak, the one-sided appearances in which it is given to me at the moment to reveal its real, objective form: "the new appearance already has entered in the composition with the lived movement and offered itself as the appearance of a cube" (p. 237). Essential to Melissa's passive constitution of the rectangular solid, to how she knows and knows about these objects, is knowing-what-happens-if the object is turned, or if I move around it. As we can see in the data (Figures 2-4), when the cube is turned, the same, unchanged caliper configuration also describes the subsequent face that is at a $90^{\circ}$ angle with the previous one. That is, in the unchanging caliper configuration that goes together with the turning of the cube exists the anticipation that the length of the face that will come up will not be different. In her movements, Melissa never represents a cube but always what is or will be experienced with or following the movement. We do not need to think of the cube in abstract and abstracted terms but simply in terms of a continuity of movements - here of the left hand rotating the cube around axes that are $90^{\circ}$ angles with respect to each other - and the continuity of observation (sensation), here, the constancy of the extensional aspects of the exposed faces. The movement of turning the object or turning around it is associated with correlated kinaesthetic and sensory experiences, and these are what knowing the object bottoms out to.

Constructivists tend to suggest that learning arises from the interpretation of objects and events (in the transitive sense of the verb "to interpret"). But when we move, there is a sense that arises from the movement itself without interpretation (Roth, 2012); we might say as the intransitive part of movement. Intentional (transitive) movements are associated with particular kinesthetic sensations that allow the reproduction and recognition of that movement. "In the effort, as we perceive and reproduce it at any instant, there is no excitation, no foreign stimulant, and yet the organ is put into play" (Maine de Biran, 1859a, p. 211). Instead, "the contraction effectuated without any cause other than that proper force that feels or perceives itself immediately in its exercise, and without that any sign can represent it in imagination or to a sense foreign to its own" (p. 211). Maine de Brian describes, thereby, the origin of symbolic movements (gestures): they arise from the first experience of kinesthesis in (unintended) movements of the body often arising from work or exploration of the material world. Once it also has symbolic character, the (gestural) movement can be associated with other symbolic forms useful in the same setting (e.g., Roth \& Lawless, 2002). When a hand adapts itself to a form by shaping itself around it—such as Melissa's hand in the black box that follows the surface of the mystery 
object-there is a (mingled) double sensation arising from kinesthesis and sensation. Recognition arises from this, when sensation and kinesthesis of a subsequent exploration of the mystery object come to be recognized as having occurred before. There is an initially spontaneous movement, giving rise to kinesthesis and sensation, before there can be a capacity to make the movement present again symbolically, that is, in the absence of the object.

Initially, therefore, there cannot be for Melissa an object independent from the movements of her hand and fingers; in fact, the movements of the hand (fingers) are tied to the material (form), which provokes particular kinetic forms as the fingers follow the surface and contours. That is, whatever form emerges - the first instance of which Melissa announces in her smile followed by the verbal articulation of "I think it's a cube" - is the result of the material form giving shape to the grasping hand and to its movement trajectory. The trajectory constitutes a particular kinetic form, a kinetic melody, which will come to be a characteristic facet of the ideal geometrical form that will be associated with the movement. The actually cognized form is the result of a sequence of movements, characterized by typical kinaesthetic and sensory experience. Even if the form comes to be denoted as a "cube" or, subsequently, as "rectangular prism," having arisen from the movement, is essentially grounded in this movement. Movement means kinaesthetic experience, a sense of the effort, and sensation that comes from the contact with the world. This is why "the geometer . . by ascending to the first element of objective knowledge, does not yet seize this element, completely abstract as it is, other then in its sensible form" (Maine de Biran, 1859a, p. 102). As experimental research shows, it is through tact and in the contact it implies that we come to have a world rather than through vision alone (Held \& Hein, 1963). Thus, touch truly is the geometrical sense (Maine de Biran, 1859b): any idea, any schema, and any ideal notion of geometry arises from, and therefore is grounded in and wedded to movement. There is no grounding problem because geometry - as subjective knowledge or objective sciencedoes not exist without movement. ${ }^{4}$ What researchers refer to as ungrounded or abstract does not deserve inclusion in the category of knowledge. Only tact "can give a basis to the originary synthetic observations of the geometer (Maine de Biran, 1859b, p. 146). That is, even if a person were to encounter a synthetic description first, it can make sense only when there are antecedent sensual (tactual) experiences; even if a teacher provides some descriptions and instructions for exploring some unknown object, the sense

4 In the cognitive sciences, the "grounding problem" refers to the disconnect between symbolic knowledge (metaphysical world, ideas, concepts) and knowing one's way around the world (physical world, ground). 
of these always follows the actual experience of moving about/around the object. This is why recent scholars suggest that we do not follow instructions but find the relevance of instructions (symbolic descriptions, plans) in situated action (e.g. Suchman, 2007).

In the episode, we twice observe the arrival of something new and unforeseen, announced as such by the learner herself. Her movements and the object encountered are pregnant in the sense that something new can come forth. Pregnance means transcendence, so that in contact with the world, new things emerge in excess of what could have been anticipated: "We assist in this event by means of which something is a thing. . . . We assist, therefore, at the coming of the positive: this rather than another thing" (MerleauPonty, 1964, p. 256). In empirical pregnance, our knowing-how concerning, and knowing-about, a thing is of a kind of "which we can have an idea of only through our carnal participation in its sense, only by espousing by our body its manner of 'signifying"' (p. 258). As a consequence, "the emergence of the Gestalt that surges from the polymorphism situates us completely outside the philosophy of the subject and the object" (p. 257), that is, completely outside constructivist epistemology. This requires us, therefore, to move towards a post-constructivist account of learning-such as the one proposed here.

When Melissa begins moving her right hand over the mystery object she does not require a representation. In fact, in the same way that military patrols move about a field in an act of reconnaissance, Melissa is on a reconnaissance mission where the mystery object gives itself because Melissa, not knowing it, cannot intentionally orient towards and construct it. She cannot have a representation of the object until after some future instant when, in the absence of the object, she can make it present again. This is what she does in her explanations to Jane and the research assistant (Figures 2-5). If anything, such movements generate representation (Held $\&$ Hein, 1963) - as we know especially from recent work on mirror neurons (Rizzolatti, Fogassi, \& Gallese, 2006). These neurons, which are active when the neuron associated with movement is active, are required for recognizing the same movement in the behaviour of another. Thus, movements can be repeated without representation; and, when these movements were associated with touching some object, they lead to the recognition of form and all the affective experiences associated with their first occurrence (Henry, 2000). This may be the reason why Sylvia's gesture of the hands held as if praying do not resonate with Melissa. It is only after kinesthetic and sensory experiences such as in Figures 6e, 6f, and 6i that the shape of the gesture and the shape of the mystery object come to be sensed and make sense. This possibility gives rise to repetition of purely 
symbolic forms. Thus, in Figure 5, the movements - which initially had ergotic (work) and epistemic function and which are associated with kinaesthesia and sensations - now also have symbolic function. They do not require representation but, following a trigger, unfold as a whole, like a kinetic melody without separate, symbolic mental representation (SheetsJohnstone, 2011). To develop anything such as knowledge that transcends the movements of the body, the latter have to exist in repeatable form and prior to any schemas that are said to underlie them. To have a schematic representation of a movement, the movement has to exist as such and prior to the fact that it can be present again.

In the episode, we see something new appear from the movements of Melissa's hand. This is possible because an experience is open towards its end and, therefore, multiplicious, even though it may initially appear unitary: there is always another way in which something can appear, always a new form of experience (Romano, 1998), always a new way of understanding something mathematically (Roth, 2013). It is this multiplicious nature of things that constitutes pregnance. Multiplicity itself is rhizomatic, exuberant, always already outside of any box that might be used in the attempt to contain it (Deleuze \& Guattari, 1980). In abstract ideas, such as the one denoted by "the cube," the multiplicity of experience - movements and their associated kinaesthesia and sensations - "is sacrificed to unity" (Maine de Biran, 1859b, p. 173). So the movements, such as the ones Melissa has effectuated in the shoebox, are fecund, giving rise to new ways of experiencing and, ultimately, to new ideations resulting in new forms of ideas. Merleau-Ponty (1964) charges that psychologists forget this productivity and fecundity that comes with and from pregnancy, a power of the bursting forth of the new. The notion of pregnancy as productivity not only of new orders but also of new perceptions lies "completely outside of Piaget's alternatives" (p. 259). There is Urstiftung [original and originary constitution], in the sense of Husserl, "rather than simple subsumption" (p. 259) to existing or accommodated schemas. From the perspective of the learner, there is transcendence rather than immediate recognition of an a priori concept. This transcendence is equivalent to the deterritorialization of the original, exploring movements into movements away from the objects associated with a symbolic world. But there is more to such a deterritorialization, such an emergence of ideas from movements and ideations, including the inherent intersubjective (objective) nature of knowing and its historically developing form. 


\section{Rethinking constructivist presuppositions}

In this study, I propose a different approach to thinking the relation between animate bodies and knowledge and, therefore, education. This approach, articulated in the analyses of the preceding section, also allows us to rethink some common constructivist presuppositions: intersubjectivity (objectivity), historicity, and the role of discrepant events (contradictions) as sources of learning.

\section{Ideation Implies Intersubjectivity and History}

Time is emergence and absenting, coming-going to presence. (Nancy, 2000, p. 104).

In and through the formation of an idea, time itself is born. This is so because the new is seen as different from the past-which Melissa specially marked by recognition and surprise in the first and second emergence of form (cube, rectangular solid). That is, there is a delay between the first contact of what comes to be recognized as one object and the related idea; there is a second temporal dimension in the emergence of the idea itself. Melissa marks, in her facial expressions, the appearance of something (cube, rectangular solid). There is a tension-laden transition, a deterritorialization, from whatever was to the newly emerging idea. The transition is not all of a sudden but has a microstructure (Petitmengin, 2006; Roth, 2012). Thus, recognition and surprise, as we see marked in and by Melissa's face, both require a past appearance to be present again together with the new and unforeseen. In the first emergence of an idea, which arises from and describes something that has preceded it - movement - also emerges time. This is captured in the opening quotation, which predicates (specifies) time as emergence (of new) and absenting (of movement), as a coming-going to presence. Time arises when a past experience comes to presence when it actually has disappeared. That is, ideation implies temporality and, therefore, historicity. But because historicity requires the making present of a past presence - i.e., representation and repetition - ideation also implies intersubjectivity. That is, even if one of these three children were to arrive at a radically new idea about geometry, it would, by its very nature, immediately be reproducible, by the same and other students, and, therefore, be intersubjective and historical. This contradicts the constructivist notion of knowledge as something singular and subjective.

Looking for the origin of the most primitive form of thought, Maine de Biran (1859a) finds it "identified in its source with the sensation of an action or a wanted effort" (p. 205). This wanted effort, together with the double 
sensation of resistance in the body attributed to the object, lies at the basis of all cognition. In the constructivist approach, however, scholars claim that the learning and developing child constructs for itself the world - through assimilation to existing schemas preceded or not by accommodation of existing schemas. Apart from the fact that this theory overlooks that both (interpretive) horizon and object change, it does not explain how the tools and subject of the construction come to be constructed in the first place. Yet more recent analyses show that the tools and subjects themselves emerge as the result of experience (Romano, 1997; Roth, 2013). In ideation, the birth of an idea as we observe in the episode, the object, subject, and tool all emerge, unpredictably, at one and the same instant. The object does not exist distinct and independent from the subject and its movement that is subject to the object. The object essentially is given in, as, and through movement. This is what allows the contention that "external perception and the perception of one's own body vary together because they are two faces of the same act" (Merleau-Ponty, 1945, p. 237).

The framework I propose here allows us to rethink the origin of time, which Piaget suggested-thereby revising Kant's notion of time as an a priori-to be the result of a construction. As shown in a celebrated analysis of the fundamental nature of everyday human consciousness, a different relation is at work between Being [Sein] and time (Heidegger, 1927/1977). How the two are connected to learning has not been explored beyond Piaget in the educational literature but is an integral consequence of an epistemology that gives primacy to movement, where "any movement creates its own space, time, and force, and thus a particular felt qualitative dynamic" (Sheets-Johnstone, 2010 , p. 226). In the emergence of an object (idea) into consciousness, there is an essential temporal aspect. The new object, as we see above, is not given once and for all. It arises from kinaesthetic and sensory movements. Then, all of a sudden, the realization of the form, a realization that itself marks a difference from what was there before, a cube, to what is there now, a rectangular prism. Ideation is a movement shifted with respect to what the idea is about, the original movement and what has spring from it. Ideation, the movement shifted with respect to itself, original/originary and symbolic, constitutes time, as the new comes to stand against what was: what is currently present is the same and different from a past presence. This difference itself, this dehiscence, is constitutive of time. There is a decalage (but not of the Piagetian kind) between movement and idea or, as shown in the celebrated but little understood Sein und Zeit [Being and Time] (Heidegger, 1927/1977), between Being [Ger. Sein] and beings, things [Ger. Seiendes]. But for the past to be present requires making it present again: re-presenting it. With ideation, therefore, comes the historicity of the idea. But, if the past can be made pre- 
sented again, represented, then it can be made present again not only by the same subject but also by other subjects. The standing out and being present to consciousness implies its iterability in general and, therefore, community and intersubjectivity. That is, rather than having to be constructed and, in essence, being unachievable - as this is assumed in the constructivist account - intersubjectivity is given with the very possibility of making something present again. Intersubjectivity also means objectivity and historicity: Geometry, as science, can be performed over and over again, simultaneously and across time, without changing (e.g., Husserl, 1976). The same experiments and the same proofs lead to the same results whoever conducts them whenever.

Besides temporality, there is another problem in constructivist approaches to knowing: how can two or more individuals know the same world in the same way. The problem arises because knowing is theorized in terms of individual consciousness and constructions rather than in terms of an inherently shared passibility of the incarnate body (flesh). In other words, in constructivist, enactivist, and embodiment approaches, intersubjectivity as a problem is an artifact of the theory. This is not the case in those approaches that are based on the primacy of movement. It is precisely because we move, because we are bodies in movement, that we share forms of experience on biological grounds that make us the same: In and through our bodies, life affects itself, and, in so doing, shows itself to itself (Henry, 2000; Ingold, 2011).

In the initial encounter of a worldly object, the movement of turning, turning around, and sensing the object - the cube in the demonstration and the mystery object in the box - there is a first experience not yet idea but no longer just raw nature. In the first contact between hand and mystery object, the movement of ideation has begun, a movement that reaches from the invisible to the seen (e.g., Roth, 2012). It has been said that "this original layer above nature shows that learning [sic] is In der Welt Sein, and not at all that In der Welt Sein is learning [sic], in the American sense or in the cognitive sense" (Merleau-Ponty, 1964, p. 262). Because the logical predicate (e.g., is In der Welt Sein) constitutes what we assert about the logical subject (e.g., learning), In der Welt Sein is what we can assert about learning rather than the other way around. We cannot assert about In der Welt Sein that it is learning. When Melissa learns-as marked in the surprise visible in her face and the subsequent actions that turn the cubiform model into a rectangular prismic one-then we can assert about it that it is a form of In der Welt Sein, being-there in and with an animate body in movement. The fundamental result of this study therefore is this: Learning is indissociable from the animate body and, therefore, the knowing-how and knowing-that associated with it. In other words, a material body does not imply learning but learning implies an (animate) material body. 


\section{Multiplicity, Bifurcations, Pregnance: On Contradictions and Differentiation}

In the literature we can find intimations that students are to be exposed to "discrepant events" and "counter intuitive demonstrations" (Lee $\&$ Byun, 2012). However, the present observations suggest that we cannot automatically assume that a situation is contradictory from the perspective of the learner. Through the eyes of Melissa, the cubical model was the appropriate one fitting her (kinaesthetic, sensory) experience, and there was no evidence for her to assume otherwise. Whenever she tested the mystery object during the preceding seven times, it was consistent with the experience of the cube in the way she demonstrated having tested (Figure 5) and articulated (Figures 2-4) the features that made the mystery object resemble the model she had constructed, that is, a cubiform entity. If there was a contradiction, it existed between the models Jane and Sylvia had constructed and her own. But the evidence that she had collected spoke against the contentions of the others. Initially, therefore, there is no contradiction between Melissa's kinesthesia and sensations related to the mystery object and cube. It is only when she does the comparison (Figure 6) that all of a sudden the differentiation emerges from kinesthesis and sensation and, in this, a contradiction between an earlier claim and the one in the process of emerging.

Initially, the movements of the right hand/fingers lead to the production of the cubiform plasticine object. What has given itself to the right hand and fingers came to be associated to the figure known as cube. Initially, and in response to Sylvia's and Jane's assertions that the mystery object was not a cube, Melissa showed how she had moved around the object with the caliper configuration (Figure 2), which, because it remained the same, was evidence for her that there was a cube. Later, when asked by the research assistant, Melissa twice does indeed provide both a gestural (symbolic) and a verbal description consistent with formal geometrical properties of a cube. In fact, there appears to be a contradiction between the movements in the first three articulations of the mystery object as a cube (Figures 2-4) and the gestural description of what Melissa says to have done (Figure 5). The subsequent movements of fingers and hands (Figure 6) give rise to a certain form of tactile experience, which is recognized to be the same as the one in the other hand, and which, in the instant of the recognition, is marked as surprise. Something unexpected has occurred: where one form of experience may have been the anticipated one, something else is born: the commonality in the kinesthesis and tactility of both hands. The movements and sensations in the right hand and fingers emerge as corresponding to the associated movements of the other side. Here, cognition of the 
object in the right hand is tied to recognition: cognition is irremediably associated with cognition, which also goes beyond what was previously known to be there.

In the present instance, a problem occurs only after a new kind of sense emerges. Melissa initially feels what she articulates to be a cube. Thus, she is modeling and holding the plasticine cube in her hands and follows its outline with her hands, a contradiction between the initial kinesthesia and sensation and the one that subsequently is related to the movement does not appear. The two kinesthesia and sensations, the one inside the box and the one outside the box, appear to be the same. The problematic of the coordination of senses in the early parts of learning already has been pointed out. The actual transfer of sense, as pointed out above, remains topologically unexplained. Paraphrasing Sheets-Johnstone (2010) we might ask, how does Melissa know that the kinetic deformations she experiences are replicable by the kinetic deformations of the plasticine she can achieve?

A contradiction, however, does not initially arise for Melissa when Sylvia and Jane say that the mystery object is not a cube, when Sylvia uses symbolic gestures to describe the mystery object, or when Sylvia and Jane show their own models (descriptions of the mystery object). The episode becomes intelligible when we think about the kinaesthetic and sensory holistic experience that comes to be differentiated in ongoing and subsequent movements, sometimes requiring particular exchanges with others. Thus, initiated by the demonstration that Jane provided and the encouragement on the part of Sylvia, Melissa uses another model to conduct a direct comparison with the mystery object. It is in this unfolding that the differentiation occurs, which then allows distinguishing between cubical and rectangular prism forms. In fact, the experience initially means likeness between the mystery object and the model at hand, which itself is different from the initially postulated and modelled cube.

Such differentiation is a general movement observed in development, such as in that pertaining to concept words. Thus, for example, students often use "heat" to denote not only the phenomenon that scientists associate with the word (i.e., energy) but also the ones referred to as temperature and entropy (Eng. hot à heat; Ger. warm à Wärme; Fr. chaud à chaleur). As those interested in food know, with increasing exposure the senses of smell and taste become increasingly differentiated and knowledgeable about differences between foods to the point of being able to indicate, during blind tasting, to locate the food items (chocolate, wine, olive oil) to the general area of production, varietal, and soil type. Differentiation allows a reconfiguration of experience. Such a reconfiguration of experience also is well known to those producing transcriptions of classroom videotapes. Even experienced 
transcribers find that what they originally heard was said changes when someone else offers a different possible hearing, or sounds that are heard but not recognized as words all of a sudden turn into clearly recognizable words.

\section{Coda}

In this study, I argue for a theoretical reorientation from the material body that enacts schemas and embodies knowledge to the movements of an animate body endowed with kinesthesia. An empirical example shows that rather than simply being embodied and associated with abstract movement schemas somehow enacted, our knowing-how and knowing-that emerge from movements of our animate bodies. In such an account, therefore, the distinction between knowing and knowing one's way around the world (i.e., movement) has been erased. "Knowledge" is thought in terms of deterritorialized movements (originary à symbolic) reterritorialized in movements of an "I can" that now anticipates certain changes in perception associated with movement. It is only in this way that the body of sense (of words, language) is the reverse side of the sense(s) of the body. It is not that abstract knowledge has to be grounded, that there is a "grounding problem," but rather, anything that can lay the claim to being epistemic, arises in and from the movements of the body. Adjectives such as embodied and enacted are artifacts of epistemologies that begin with and privilege the mind over the body rather than constituting epistemologies that are sound on evolutionary and cultural-historical grounds. If such adjectives and concepts as "enacted schemas" and "embodied concepts" are to have any sense, the very point of emergence of these schemas and concepts needs to be demonstrated. On biological grounds, (human) schemas and concepts are evolutionary latecomers. Their origin has to be explained without drawing on a priori and innate knowledge - a form of reasoning that uses the explanandum (what is to be explained) to explain the explanans (that which explains). The post-constructivist approach proposed here simultaneously is a pre-constructivist epistemology. It establishes the possibility of any so-called embodied or enacted schema. Before a process of construction sets in, the tools of the construction need to be explained. On philosophical and evolutionary grounds, which reconstruct the beginning of life in motility and sensation, self- movement and self-affection are the origins of any higher conscious form of life. Because movement and kinetic melodies constitutes their own memory, no (mental) schemas are necessary. In fact, the mental schemas are the result when movement comes to be deterritorialized rather than being instinctive and, therefore, transcend themselves that any schema can emerge. What 
enactivist scholars refer to as "enactment" is in fact a reterritorialization in the world of a previously deterritorialized movement. Willed acts come about when spontaneous movement come to unfold after some conscious mental act consistently triggers their release and unfolding.

The geometrical object - such as the (ideal) cube - is a limit idea arising from continuous refinement of actual objects encountered in practical experience (movements), a refinement that can only in the unachievable limit become consistent with geometrical properties (Husserl, 1976). Practical experiences, such as we see them in Melissa's movement, are sedimented in and underlie any geometrical knowledge. In the present study, we observe a differentiation that is required before the refinements of the cube can occur: the differentiation of cubical from other, similar forms. This movement of differentiation itself comes to be sedimented to constitute the fundamental sense, the ultimate ground of any geometrical concept of three-dimensional forms.

In the episode, we observe hand movements both over a model object (Figures 2-4) and on their own (Figure 5) used to explain why the mystery object should be a cube. There also is observable a conceptualization, a mode of transcendence or deterritorialization. Thus, in Figure 5, Melissa shows what she has done, repeats the movements that have earlier arisen while following and sensing the mystery object. These movements, however, differ from the ones she previously used to "prove" why the mystery object has cubical form: the caliper configuration held to the model is the same for the different faces. We do not know whether Melissa's hands have moved like this ever before. In any event, to be intentionally enacted, the body needs to know that these movements are part of its powers, part of an "I can." That is, it has moved in this manner at least once before. The same movements can be executed in the absence of the original form associated with them; and they can be recognized only when they have been cognized before. Thus, it is in this way that there is a transfer from the movements that the hand has made following the mystery object to gesturing the movements as part of the argument that it has cubicle form. It also lies at the origin of the recognition that occurs when some other material of the same form is followed.

In conclusion, then, the original movements in the shoebox are the originary and original signs of diverse elementary perceptions related to them; these movements cannot be separated from the primary qualities that come from the resistance of the movement to itself (associated with kinesthesia) and the resistance deriving from the outside object. The movements, therefore, can actually serve to recall, bring back, the ideas associated with them; and this recall, in turn, is the fundamental experience and memory in which words and language are grounded. Whatever we know about the world al- 
ways and already is grounded in and arises from bodily movements, or, more exactly, the kinesthesia and sensations associated with them. When we say that something "makes sense" or "is meaningful," we address precisely this association of sound-words with original movements, kinesthesia and sensations, in the social and material world.

\section{References}

Deleuze, G., \& Guattari, F. (1980). Mille plateaux: Capitalisme et schizophrénie [A thousand plateaus: Capitalism and schizophrenia]. Paris, France: Les Éditions de Minuit.

Heidegger, M. (1977). Sein und zeit [Being and time]. Tübingen, Germany: Max Niemeyer. (First published in 1927)

Held, R., \& Hein, A. (1963). Movement-produced stimulation in the development of visually guided behaviour. Journal of Comparative and Physiological Psychology, 56, 872-876.

Henry, M. (2000). Incarnation: Une phénoménologie de la chair [Incarnation: A phenomenology of the flesh].Paris, France: Éditions du Seuil.

Husserl, E. (1973). Husserliana Band I: Cartesianische mediationen und pariser vorträge [Husserliana vol. 1: Cartesian meditations and Paris lectures]. The Hague, The Netherlands: Martinus Nijhoff.

Husserl, E. (1976). Husserliana Band VI: Die Krisis der europäischen Wissenschaften und die transzendentale Phänomenologie. Eine Einleitung in die phänomenologische Philosophie [Husserliana vol. 4. The crisis of the European sciences and transcendental phenomenology. An introduction to phenomenological philosophy]. The Hague, The Netherlands: Martinus Nijhoff.

Ingold, T. (2011). Being alive: Essays on movement, knowledge and description. London, UK: Routledge.

Lee, G., \& Byun, T. (2012). An explanation for the difficulty of leading conceptual change using a counterintuitive demonstration: The relationship between cognitive conflict and responses. Research in Science Education, 42, 943-965.

Leont'ev, A. N. (1959). Problemy razvitija psixhiki [Problems of mental development]. Moscow, USSR: Idastel'stvo Akademii Pedagogičeskix Nauk.

Maine de Biran, P. (1859a). OEuvres inédites, tome 1 [Unpublished works vol. 1]. Paris, France: Dezobry and Magdeleine.

Maine de Biran, P. (1859b). OEuvres inédites, tome 2 [Unpublished works vol. 2]. Paris, France: Dezobry and Magdeleine.

Merleau-Ponty, M. (1945). Phénoménologie de la perception [Phenomenology of perception] Paris, France: Gallimard.

Merleau-Ponty, M. (1964). Le visible et l'invisible. Paris, France: Gallimard.

Nancy, J.-L. (2000). Corpus [Corpus]. Paris, France: Métaillé.

Petitmengin, C. (2006). L'énaction comme expérience vécue [Enaction as lived experience]. Intellectica, 43, 85-92.

Petitmengin, C. (2007). Towards the source of thoughts: The gestural and transmodal dimensions of lived experience. Journal of Consciousness Studies, 14, 54-82. 
Rizzolatti, G., L. Fadiga, V. Gallese, \& L. Fogassi. (1996). Premotor cortex and the recognition of motor actions. Cognitive Brain Research, 3, 131-141.

Rizzolatti, G., Fadiga, L., Fogassi, L., \& Gallese, V. (1997). The space around us. Science, 277, 190-191.

Rizzolatti, G., Fogassi, L., \& Gallese, V. (2006). Mirrors in the mind. Scientific American, 295 (5), 54-61.

Romano, C. (1998). L'événement et le monde [Event and world]. Paris, France: Presses Universitaires de France.

Roth, W.-M. (2012). Mathematical learning: The unseen and unforeseen. For the Learning of Mathematics, 32 (3), 15-21.

Roth, W.-M. (2013). To event: Towards a post-constructivist approach to theorizing and researching curriculum as event*-in-the-making. Curriculum Inquiry, 43, 388-417.

Roth, W.-M., \& Jornet, A. G. (2013). Situated cognition. WIREs Cognitive Science, 4, 463-478.

Roth, W.-M., \& Lawless, D. (2002). Scientific investigations, metaphorical gestures, and the emergence of abstract scientific concepts. Learning and Instruction, 12, 285-304.

Roth, W.-M., \& Radford, L. (2011). A cultural-historical perspective on mathematics teaching and learning. Rotterdam: Sense Publishers.

Roth, W.-M., \& Thom, J. (2009a). Bodily experience and mathematical conceptions: From classical views to a phenomenological reconceptualization. Educational Studies in Mathematics, 70, 175-189.

Roth, W.-M., \& Thom, J. (2009b). The emergence of 3d geometry from children's (teacher-guided) classification tasks. Journal of the Learning Sciences, 18, 45-99.

Sheets-Johnstone, M. (2009). The corporeal turn: An interdisciplinary reader. Exeter, UK: Imprint Academic.

Sheets-Johnstone, M. (2010). Body and movement: Basic dynamic principles. In S. Gallagher \& D. Schmicking (Eds.), Handbook of phenomenology and cognitive science (pp. 217-234). Dordrecht, The Netherlands: Springer.

Sheets-Johnstone, M. (2011). The primacy of movement (2nd ed.). Amsterdam, The Netherlands: John Benjamins.

Suchman L. A. (2007). Human-machine reconfigurations: Plans and situated actions (2nd ed.). Cambridge, UK: Cambridge University Press.

\section{Author:}

Wolff-Michael Roth, Lansdowne Professor

University of Victoria

Applied Cognitive Science

MacLaurin Building A557

Victoria, BC

V8W 3N4

Canada

email: mroth@uvic.ca 